\title{
Splash and Bubbles for Parents App: Field Study Report
}

Ximena Dominguez, Elizabeth Rood ${ }^{1}$, Danae Kamdar, Tiffany Leones, and Kayla Huynh

June 2021

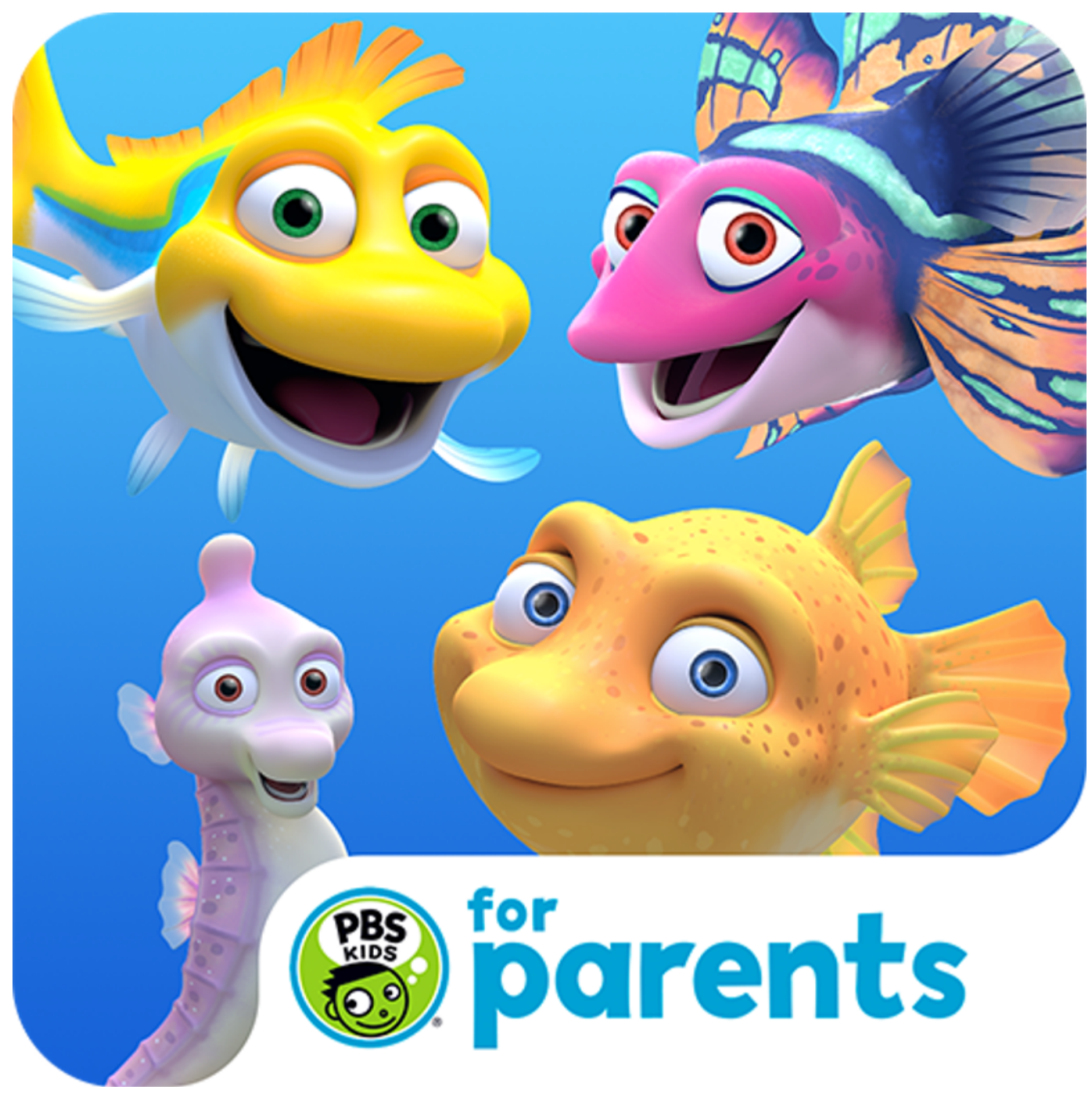

Digital

${ }^{1}$ All authors are staff of Digital Promise except for Elizabeth Rood (Learning Designs Consulting, LLC.) 


\section{Suggested Citation}

Dominguez, X., Rood, E., Kamdar, D., Leones, T., \& Huynh, K. (2021). Splash and Bubbles for Parents App: Field Study Report [Project Report]. Digital

Promise. https://doi.org/10.51388/20.500.12265/119

\section{Acknowledgments}

This material is based upon work supported by the National Science

Foundation under Grant No. 1612840. Any opinions, findings, and conclusions or recommendations expressed in this material are those of the author(s) and do not necessarily reflect the views of the National Science Foundation.

\section{Contact Information}

Email: xdominguez@digitalpromise.org

Digital Promise:

Washington, DC:

1001 Connecticut Avenue NW, Suite 935

Washington, DC 20036

San Mateo, CA:

2955 Campus Dr. Suite 110

San Mateo, CA 94403

https://digitalpromise.org/ 


\section{Executive Summary}

The Splash and Bubbles for Parents app is a second-screen digital resource for parents and caregivers to support young children's learning of ocean science. This report, prepared for The Jim Henson Company, shares findings of a field study conducted to examine the promise of the app in supporting parents' and caregivers' behaviors and attitudes toward science and technology; families' joint engagement with media (adults and children watch and play together); and children's science learning. Findings indicate that parents and caregivers found the app helpful for supporting their children's science learning. Parents and caregivers in the intervention group (who watched the show and used the app) initiated more conversations before and after viewing episodes, relative to parents and caregivers in the comparison group (who watched the show but did not have access to the app). Furthermore, parents and caregivers in the intervention group facilitated more science conversations, relative to parents and caregivers in the comparison group. It is important to note that families who used the app's features more extensively seem to have better internalized the purpose of the app and spent more time exploring and using its components. Families who explored the app often and more deeply also reported stronger self-reported changes in joint media engagement and science. Many families, however, would benefit from support navigating the app given it represents a new kind of tool. Finally, while differences in children's understanding of the science concepts in the show were not detected between groups, the proportion of science-related conversations initiated by children before and after episode viewing was higher for children in the intervention group. 


\section{Introduction}

The Splash and Bubbles for Parents app is a second-screen digital resource for parents and caregivers to support young children's learning of ocean science developed as part of a National Science Foundation (NSF) grant (see detailed description of the app below). Digital Promise's Early STEM Learning research team conducted a field study in 2020 to examine the promise of the app in supporting parents' and caregivers' behaviors and attitudes toward science and technology; families' joint engagement with media (adults and children watch and play together); and children's science learning. The study involved a two-group, quasiexperimental design in which family participants were randomly assigned to either the intervention condition or the comparison condition. Families in the intervention condition watched Splash and Bubbles episodes and interstitials (short video clips highlighting a science theme from the show, oftentimes related to an episode) and used the Splash and Bubbles for Parents app developed as part of the project. Families in the comparison condition watched Splash and Bubbles episodes and interstitials but did not have access to the app.

The field study sought to address the following research questions:

1. How do families use the app-when, how often, and in what social arrangements?

2. To what extent does app use encourage and support rich, extended discourse about science between parents/caregivers and children?

3. To what extent do joint engagements supported by the app support children's development of ocean science content knowledge and science practices?

4. To what extent do parent/caregiver behaviors, attitudes, and beliefs about educational media, ocean science, and family support for learning change as a result of engagement with the app?

This report provides an overview of research activities and findings from the field study. ${ }^{2}$ Sources of data include parent/caregiver surveys, interviews, and text message data; visits and observations of families; and child science assessment tasks.

\section{Splash and Bubbles for Parents App}

The Splash and Bubbles for Parents app is a second-screen app designed to work in conjunction with an ocean science-focused children's television program, Splash and Bubbles, produced by The Jim Henson Company and freely available on PBS KIDS platforms. Rooted in adults' reporting widespread usage of a second-screen device while watching television (Clement, 2019), the Splash and Bubbles for Parents app expands on this notion by creating a second-screen tool aimed at supporting and promoting science-rich talk between adults and children and facilitating joint engagement with media. Formative research, which included a context study and several pilot studies, informed the app development and design.

\footnotetext{
${ }^{2}$ It is important to note that the study sample is small and that differences noted were therefore not tested for significance.
} 
The purpose of the context study was to identify and describe families' current practices around technology and media use as well as science learning to guide initial app development. Later pilot studies provided families with an opportunity to test app prototypes and share valuable feedback on specific app features leading to further app refinement. The app provides families with related content (e.g., video clips, information about characters, and themes), conversation starters to support science talk before, during, and after episode viewing, and activity ideas for families to explore the scientific ideas in the show at home or in their community in engaging and hands-on ways. As a second-screen resource, the app aims to support families' joint engagement with media in real time. A unique feature of the app utilizes Automatic Content Recognition (ACR) technology to allow automatic syncing to the episode being watched. This allows parents/caregivers to access related content easily.

\section{Conversation Starters: "Let's Talk About It"}

To help parents/caregivers facilitate rich science conversations with their children and scaffold children's understanding of the science ideas in the show, the app contains a set of conversation starters for each episode that can be accessed automatically via the sync feature and/or by searching for a given episode. It includes conversation starters for first viewings (the first time children view an episode), as well as for repeat viewings. For each of these use cases, parents/caregivers can find ideas and support to promote science talk before, during, and after viewing the episode.

First viewing prompts are designed to help contextualize the science content by focusing on the episode narrative and introducing some of the science ideas in the show. The repeat viewing prompts focus more heavily on the science ideas and invite children to engage in science discourse (i.e., providing explanations based on what they have viewed). Generally, before viewing prompts encourage children to make predictions about what they may notice or find out in the episode. The during viewing prompts often provide a strategic pause point for the viewer to notice something important in the episode. The after viewing prompts often facilitate reflection to help children understand and further explain something that happened in the episode.

\section{Hands-on Learning: Activity Cove}

The Activity Cove is a collection of short and engaging learning activities that families can easily try at home, outdoors, or in their community. The activities are designed to extend children's understanding of the science ideas introduced in the show by connecting them to children's everyday experiences. Some activities include a "Snap It" component to encourage families to take photos of their science adventures, which can be later accessed through a Photo Journal. 


\section{Study Participants}

\section{Recruitment and Total Sample}

Leveraging partnerships with early childhood centers and public schools serving diverse populations in the San Francisco Bay Area, we recruited a total of 30 families to participate in the study. Each family unit consisted of one focal parent/caregiver and at least one prekindergarten or kindergarten-aged child. Families were enrolled on a rolling basis and randomly assigned to a condition (intervention or comparison), stratifying by school and gender. As an incentive to participate, each family received a Kindle Fire tablet. Families also received a $\$ 150$ gift card at the end of the study.

\section{Study Participation during COVID-19}

Families were in various stages of the study at the onset of the COVID-19 pandemic. For logistical and data analytic purposes, we grouped families who completed all observation sessions in-person into Cohort 1. Families, who were mid-course in the study and had at least one in-person observation session followed by remote virtual sessions, were grouped into Cohort 2. Attrition was low with only one family not completing the study.

A total of 16 families with 17 children comprised Cohort 1. Seven of the Cohort 1 families were randomly assigned to the intervention condition and nine families were randomly assigned to the comparison condition. Families in both conditions were similar on various characteristics (e.g., child age, child gender, and parent level of education). While child demographics and parent level of education was comparable across the two conditions (see Table 1 and Table 3), parent racial/ethnic identity differed. The comparison group consisted of a higher percentage of participants who identified as Hispanic or Latino in contrast to the intervention group which had more participants self-identify as not Hispanic or Latino, namely Asian. This may be attributed to the demographics of participants in the initial schools recruited. To account for this, subsequent efforts aimed at recruiting participants in schools with different demographics yet the sample remained imbalanced. Furthermore, although the percentage of participants that reported either one language spoken at home or more than one language spoken at home were similar between conditions, there were some differences in regard to language (see Table 3). For those who reported more than one language spoken at home, there was more variability in the combination of the two languages spoken by intervention participants as opposed to only Spanish and English reported by comparison participants. Interestingly, none of the intervention participants reported only English spoken at home. Differences related to racial/ethnicity and languages spoken at home across the intervention and comparison conditions could be associated with different patterns of app use and perceived usefulness and warrant further investigation. 
Table 1

Child Gender and Age by Condition

\begin{tabular}{|l|l|l|l|l|}
\hline & \multicolumn{2}{|l|}{ Child Gender } & \multicolumn{2}{l|}{ Child Age } \\
\cline { 2 - 5 } & Female & Male & 5 & 6 \\
\hline Full sample $(n=17)^{3}$ & $29.41 \%$ & $70.49 \%$ & $88.24 \%$ & $11.76 \%$ \\
\hline Intervention $(n=7)$ & $28.57 \%$ & $71.43 \%$ & $85.71 \%$ & $14.29 \%$ \\
\hline Comparison $(n=10)$ & $30 \%$ & $70 \%$ & $90 \%$ & $10 \%$ \\
\hline
\end{tabular}

Table 2

Languages Spoken at Home by Condition

\begin{tabular}{|l|l|l|l|l|l|l|}
\hline \multirow{2}{*}{} & \multicolumn{3}{|l}{$\begin{array}{l}\text { One Language Spoken at } \\
\text { Home }\end{array}$} & \multicolumn{2}{l|}{ More Than One Language Spoken at Home } \\
\cline { 2 - 7 } & English & Chinese & Spanish & Spanish/English & Chinese/English & Tagalog/English \\
\hline $\begin{array}{l}\text { Full sample } \\
\text { (n=16) }\end{array}$ & $18.75 \%$ & $18.75 \%$ & $12.5 \%$ & $37.5 \%$ & $6.25 \%$ & $6.25 \%$ \\
\hline $\begin{array}{l}\text { Intervention } \\
(n=7)\end{array}$ & $0 \%$ & $28.57 \%$ & $14.29 \%$ & $28.57 \%$ & $14.29 \%$ & $14.29 \%$ \\
\hline $\begin{array}{l}\text { Comparison } \\
\text { (n=9) }\end{array}$ & $33.33 \%$ & $11.11 \%$ & $11.11 \%$ & $44.44 \%$ & $0 \%$ & $0 \%$ \\
\hline
\end{tabular}

\footnotetext{
3 One family in the comparison group had twins participate in the study activities.
} 
Table 3

Parent Demographics by Condition

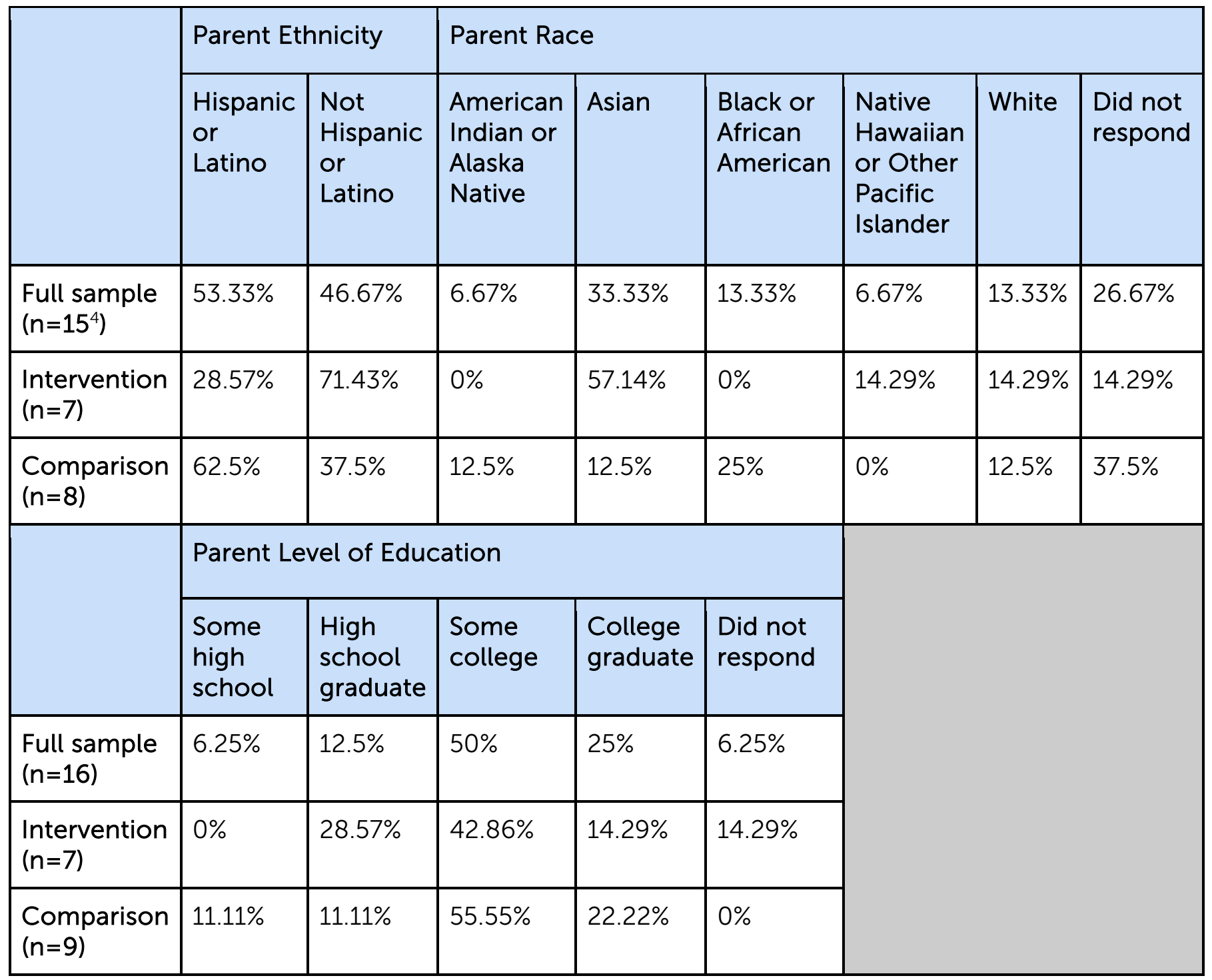

4 One participant in the comparison group did not complete the pre-survey, which included information about parent ethnicity and race. 


\section{Study Details}

\section{Family Participant Experience}

Over approximately a seven-week period, families in both conditions were asked to watch 15 episodes and five interstitials. The research team curated and selected the 15 episodes to address three science core ideas prevalent in the Splash and Bubbles show: structure and function; interdependent relationships; and adaptations.

Families in both conditions were provided a Kindle Fire tablet with the curated episodes and interstitials loaded onto a miniSD card. Families in the intervention condition were asked to download the app and were encouraged to use the app as part of their experience. More specifically, intervention families were invited to use the conversation starters when watching episodes and asked to try out three activities. At the conclusion of the study, parents/caregivers in the comparison condition were informed about the app.

\section{Data Collection}

To assist with data collection, the research team trained five research assistants with early childhood, teaching, and/or research experience on the observation protocol used during inperson sessions and the child assessment designed as part of the study. Research assistants were engaged in approximately two days of training/reliability activities.

\section{Surveys}

Each focal parent/caregiver was invited to complete an online survey at the start and end of the study. The survey was designed to elicit parent/caregiver attitudes, beliefs, and practices on science learning and the use of technology and media. The post-survey included additional questions on the use of the app for intervention participants.

Of the Cohort 1 families, there were a total of 15 matched pre- and post-surveys (seven families in the intervention condition and eight families in the comparison condition). One comparison family did not complete the pre-survey.

\section{Interviews}

To better contextualize the survey responses, we conducted follow-up phone interviews with each focal parent/caregiver at the start and end of the study. The pre-interview included questions specific to families' practices around joint engagement and science and science talk. All Cohort 1 parents/caregivers completed pre- and post-interviews.

\section{In-Person Sessions/Observations}

The purpose of the in-person sessions/observations was to observe and document how parents and children interact with one another around the Splash and Bubbles show and, for the intervention families, how parents use the app to promote conversations with their children and support children's learning. Each participating family was visited/observed three 
times during the study. Each in-person session was followed by two weeks of at-home viewing. See Appendix A for a detailed schedule by condition.

At the start of each in-person session, research assistants recorded who was in attendance. Families were asked questions related to prior science knowledge during the first in-person session and questions related to the Splash and Bubbles episodes in subsequent sessions. Additional app-related questions were posed only to intervention families. As families watched two assigned episodes during each in-person session, research assistants took notes and documented the conversations between the parents/caregivers and their children. Research assistants also documented intervention families' use of the app.

\section{Text Messages}

Between each in-person session/observation, intervention, and comparison, parents/caregivers received text message reminders about upcoming assignments. In the case of intervention participants, text message data also documented the frequency with which families accessed the app (dosage), parents'/caregivers' opinions of the extent to which the app facilitated engagement with children around the media, and parents'/caregivers' perceptions of the app.

\section{Child Assessment}

A set of developmentally appropriate, game-like learning tasks was designed to evaluate children's understanding of target science core ideas. To develop the set of assessment tasks, the team used the learning blueprint generated during the design phase of this project as a guide. The blueprint details science learning goals aligned to the disciplinary core ideas identified in the Next Generation Science Standards (NGSS) and science learning goals aligned to science practices identified across multiple resources, including the NGSS and the Head Start Outcomes Framework. Given the target science core ideas (related to ocean science) presented in the Splash and Bubbles episodes, the team relied heavily on the use of photos to provide familiar context for children without aligning directly to the episodes and its characters.

A research team member administered the tasks one-on-one with each participating child prior to the first in-person session and after the final in-person session. The assessment was conducted at the child's school and lasted approximately 10 minutes. In Cohort 1, there were a total of 16 matched pre- and post-assessments across 15 families. The child in the remaining Cohort 1 family only completed a pre-assessment. Due to COVID-19, we were unable to administer post-assessments in-person for children in Cohort 2. As a result, the team adapted the assessment in order to administer virtually using screen share on Zoom. 


\section{Cohort 1 Findings}

\section{Research Question 1: How do families use the app-when, how often, and in what social arrangements?}

Throughout the intervention, we collected information on how often parents/caregivers in the intervention condition used the app. This data was collected from parents'/caregivers' self-reports (via text messages, surveys, and interviews) and research assistants' observations during in-person sessions.

Most intervention participants reported using the app to some degree throughout the study. Between Session 1 and Session 2, six out of the seven intervention participants reported via the text message responses that they had watched the assigned episodes. Of the six participants, five reported using the app that week. In the post-survey, parents/caregivers were asked to think back to the prior week and indicate the frequency they used the app: never; 1-2 times a week; 3-4 times a week; every day. For the most part, participants' responses via text message aligned with their self-report in the post-survey. Of the five participants who reported using the app via text message, three reported using the app 1-2 times a week and the other two reported using the app more frequently at 3-4 times a week. There was one family who reported using the app 1-2 times in the post-survey but did not receive the initial text question about episode watching and thus did not receive the followup text question about app use.

Interview data was also analyzed to further understand patterns of app use. Analysis of the interview data also indicates that parents'/caregivers' use of the app varied considerably across families. Families who used the app's features more extensively seem to have better internalized the purpose of the app and spent more time exploring its components and experimenting with its use during co-viewing sessions. Families who explored the app most often and more deeply also reported stronger self-reported changes in joint media engagement and science. For these reasons, the researchers conclude that a more robust orientation to the app would likely increase the effectiveness of the app as a tool for parents, especially because an app for parents designed to accompany a children's show is a new type of tool for many families.

Finally, during in-person sessions, research assistants recorded whether families looked at the app before, during, and afterviewing the episodes. In the first session, all intervention parents/caregivers looked at the app before viewing the first episode they watched with their children. Across the remaining sessions, the frequency in which they looked at the app before, during, and after viewing the episodes varied. Overall, however, families tended to look at the app before watching the episode more frequently than during or after viewing the episodes. Because parents may have looked at all conversation starter sections (before, during, and after) prior to episode watching, observers also documented detailed conversations between parents and children at each of these times to code adult and child initiation and identify whether and how app use is associated with science discourse (see section below). 


\section{Research Question 2: To what extent does app use encourage and support rich, extended discourse about science between parents/caregivers and children?}

As part of the post-study survey, intervention parents/caregivers were asked to rate how much they think the Splash and Bubbles for Parents app supports them in helping their children learn about science on a scale from 1 (not very helpful) to 5 (very helpful). The average rating across the seven intervention families was a 4 with none of the participants rating the app anything lower than 3 . Similarly, all except one participant reported that they were likely to refer the app to others.

Across all three in-person sessions, research assistants documented whether families used any prompts from the app and any keywords used during exchanges with children. Of the seven intervention families, four families were observed using a prompt at least once during one of the sessions. Of these four families, two used both first and repeat viewing prompts on at least one occasion, while the remaining two only used first viewing prompts. The number of first viewing prompts was almost double the number of repeat viewing prompts, which may be in part due to a couple of families not being aware of the latter (possibly due to the app design utilizing a "Switch Viewing" button).

We recognize that in addition to and/or instead of using the prompts verbatim, families may have been inspired by prompts in the app and engaged in related conversations. To further investigate the potential impact of the app on science discourse, observers documented and coded families' conversations before, during, and after episode viewings. Analysis of these data indicates that, across conditions, adults (parents/caregivers) initiated more conversations during episode viewings, relative to before or after episode viewings. See Figures 1, 2, and 3. Interestingly, however, the patterns of adult initiations during episode viewings were not different across intervention and comparison conditions (see Figure 2). On the other hand, even though initiations before and after episode viewing were less frequent than initiations during episodes, adults in the intervention condition tended to initiate more conversations in those moments than parents in the comparison condition. See Figures 1 and 3. These findings highlight the promise of the app in supporting family conversations, especially those that occur before or after viewing. 


\section{Figure 1}

Frequency of Adult Initiations Before Episodes

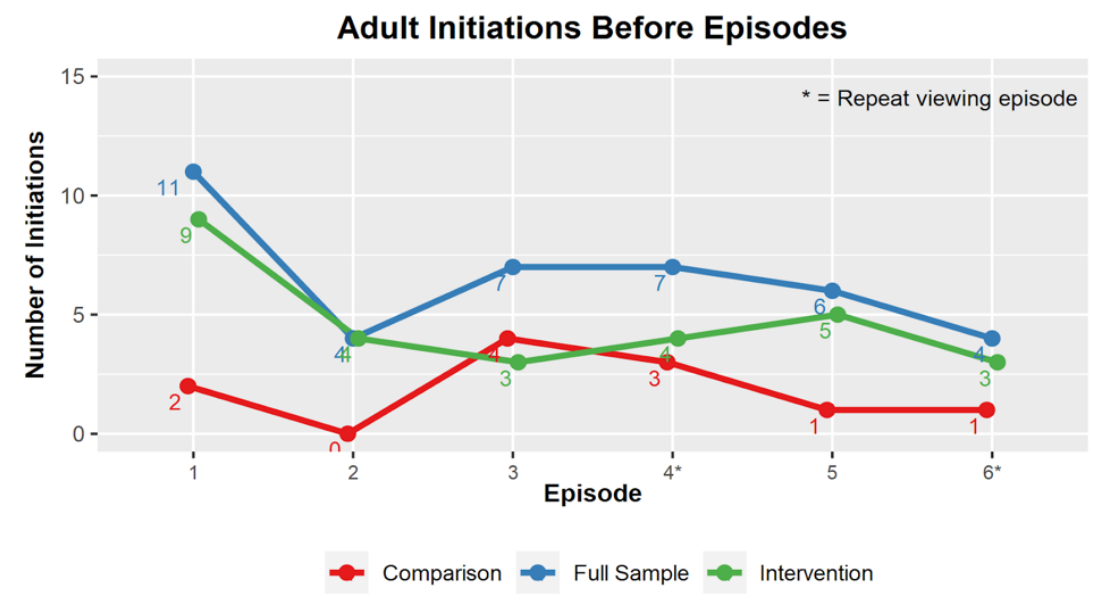

\section{Figure 2}

Frequency of Adult Initiations During Episodes

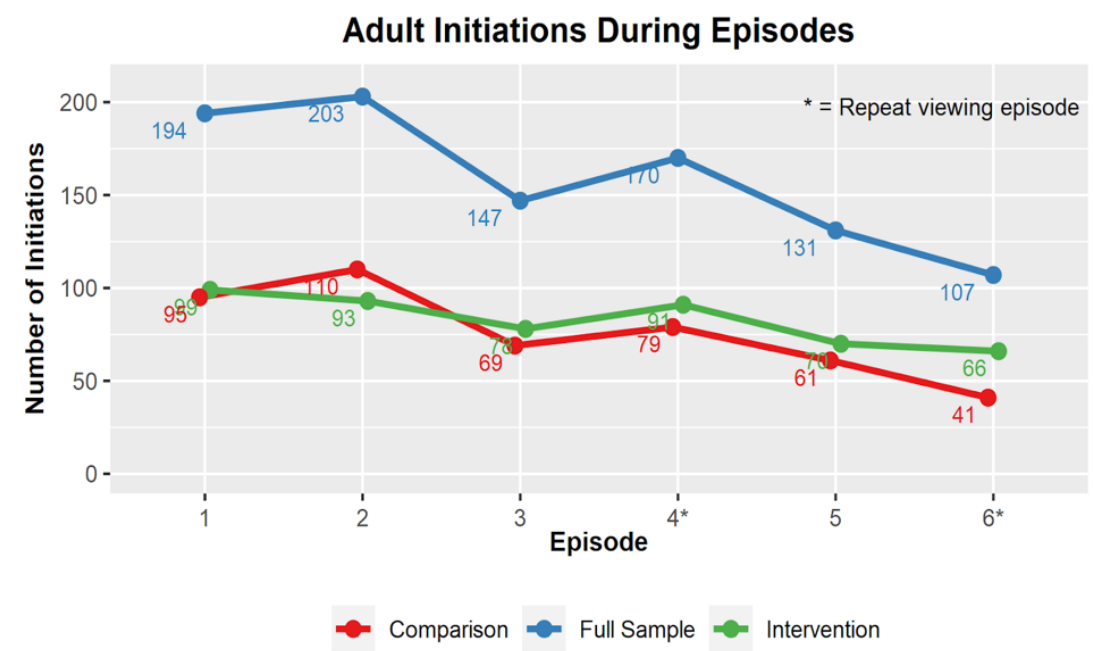


Figure 3

Frequency of Adult Initiations After Episodes

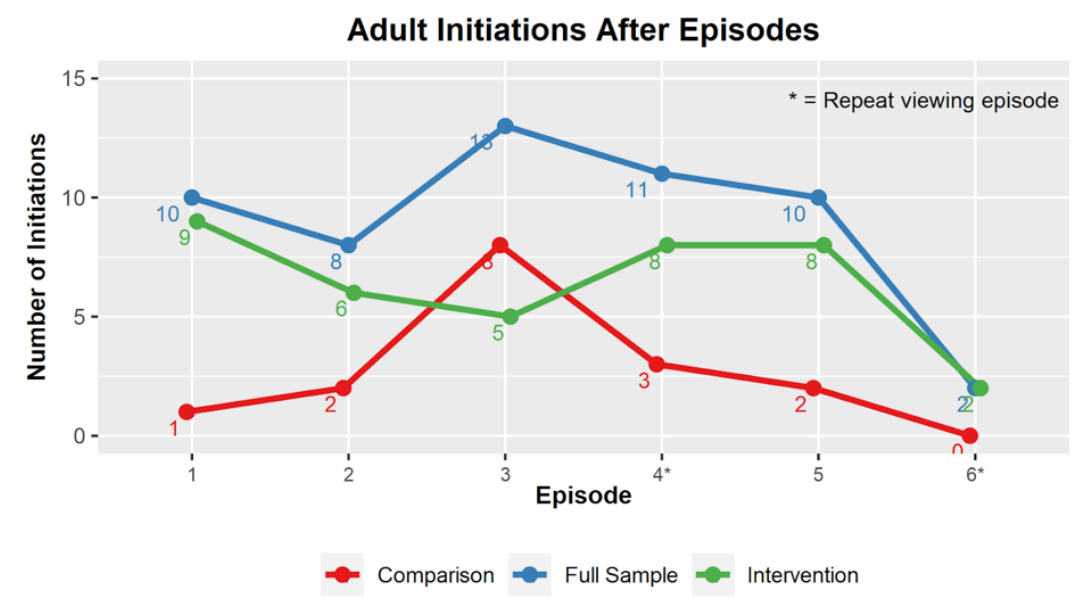

As part of the analyses, the team also coded the degree to which the conversations between adults and children were science related. Each conversation prompt was coded as (a) addressed science, (b) addressed science peripherally, or (c) did not address science. Table 4 shows examples of conversations coded into these science-related talk categories.

\section{Table 4}

Science Related Talk Conversation Examples

\begin{tabular}{|c|c|c|}
\hline Code & Adult Initiated Example & Child Initiated Example \\
\hline Science & $\begin{array}{l}\text { A: What did Oblo say } \\
\text { about his bones? What } \\
\text { are they like? } \\
\text { C: Soft, like a Jello soft } \\
\text { A: Yeah, soft. } \\
\text { C: I said Jello soft bones. } \\
\text { A: Yeah he has only soft } \\
\text { bones and is squishy and } \\
\text { soft. } \\
\text { C: Yeah soft squishy. }\end{array}$ & $\begin{array}{l}\text { C: His body is made out of jelly. } \\
\text { A: Do you know why? } \\
\text { C: Why? } \\
\text { A: Because his bones are soft so he doesn't } \\
\text { break. Like if I bent this, you see how it's hard so } \\
\text { it would break, but he is all soft. }\end{array}$ \\
\hline $\begin{array}{l}\text { Peripheral } \\
\text { Science }\end{array}$ & $\begin{array}{l}\text { A: Where are they going? } \\
\text { C: To the deep ocean } \\
\text { where Splash's friend is! }\end{array}$ & $\begin{array}{l}\text { C: If they get scared, they could hold fins. } \\
\text { A: Like this! (Holds hand) }\end{array}$ \\
\hline Not Science & $\begin{array}{l}\text { A: What are they playing? } \\
\text { C: Hide and Seek. }\end{array}$ & $\begin{array}{l}\text { C: What's his name? } \\
\text { A: They're going to find Lu. }\end{array}$ \\
\hline
\end{tabular}


Overall, intervention families tended to have a larger proportion of conversations that addressed science than the comparison families. While differences were noted across conditions in science-related discourse both before and after episode viewings, a stronger difference is evident for after episode viewings. Approximately, $64 \%$ of the intervention families' after episode viewing prompts were found to address science, while only $32 \%$ of prompts from comparison families were science related (see Figure 4). For before episode viewing prompts, $25 \%$ of the intervention families' prompts addressed science compared to approximately $17 \%$ of the comparison families' science-related prompts.

\section{Figure 4}

Percentages of Science-Related Prompts After Episodes by Condition

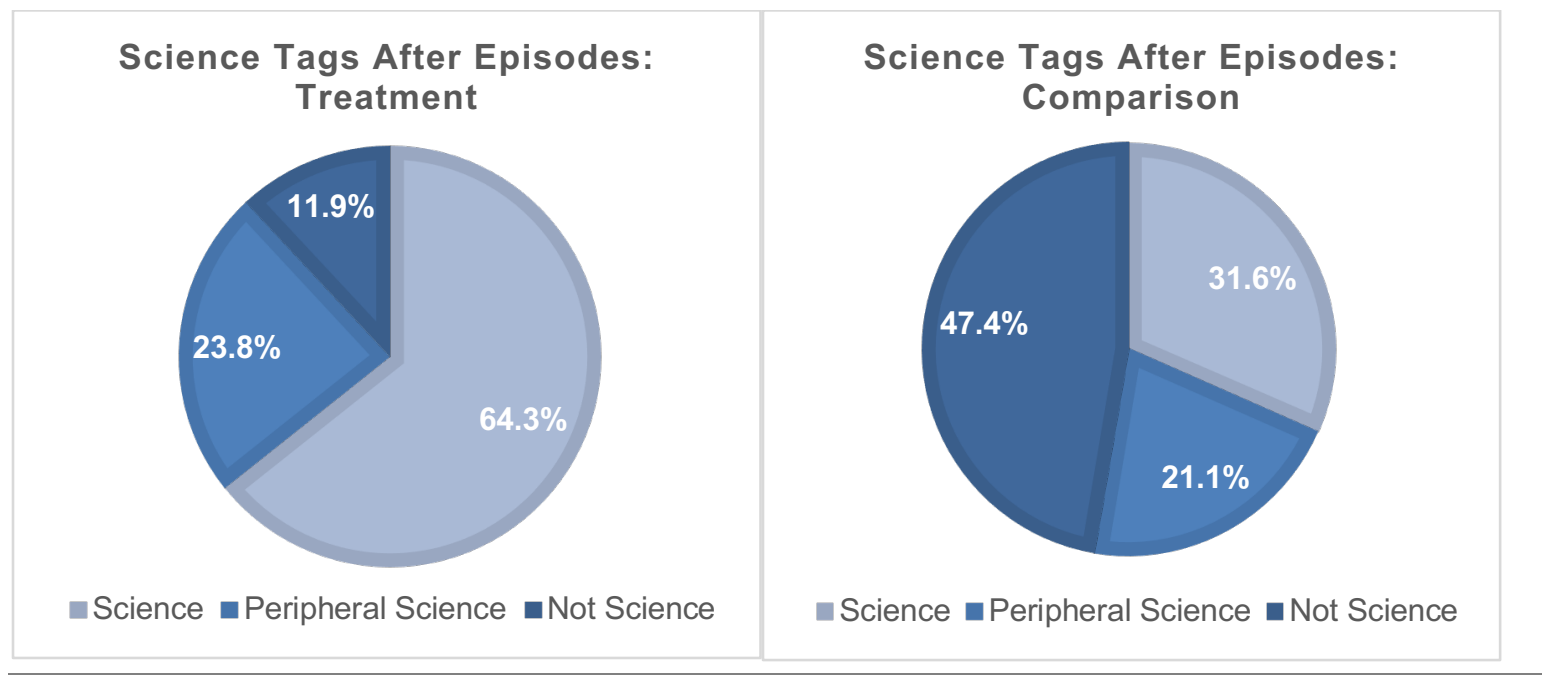

To further examine adult initiations, we also coded each initiation to determine what kind of talk moves it involved. Table 5 below describes how initiations were coded into talk moves and documents which talk moves were highlighted/expected to be used before, during, and after episode viewing more frequently when using the app. We did not expect all of these talk moves to be equally frequent. In fact, some initiations are more likely to occur before, during, or after viewing. In addition, the app by design highlighted some of the talk moves in the different conversation starter sections. For instance, predictions were often included in before viewing prompt sections while extending ideas/reflection was more often included in after viewing prompts. 
Table 5

Talk Move Types

\begin{tabular}{|c|c|c|c|c|c|c|}
\hline Adult Talk Move Type & Label & Description & Example & $\begin{array}{l}\text { Expected } \\
\text { Before }\end{array}$ & $\begin{array}{l}\text { Expected } \\
\text { During }\end{array}$ & $\begin{array}{l}\text { Expected } \\
\text { After }\end{array}$ \\
\hline Asks a question & Asks & $\begin{array}{l}\text { Broad } \\
\text { category to } \\
\text { capture brief, } \\
\text { closed- } \\
\text { ended } \\
\text { questions or } \\
\text { more } \\
\text { complex } \\
\text { open-ended } \\
\text { questions }\end{array}$ & $\begin{array}{l}\text { "What } \\
\text { episode did } \\
\text { you like } \\
\text { better?" }\end{array}$ & $\sqrt{ }^{*}$ & $\checkmark$ & $\sqrt{ } *$ \\
\hline Calls attention to show & Calls & $\begin{array}{l}\text { Focuses } \\
\text { child's } \\
\text { attention on } \\
\text { an aspect of } \\
\text { the show - } \\
\text { this could be } \\
\text { a character, } \\
\text { location, } \\
\text { story, etc. }\end{array}$ & $\begin{array}{l}\text { "Look, they } \\
\text { are still } \\
\text { looking for } \\
\text { the } \\
\text { seahorse." }\end{array}$ & & $\checkmark$ & \\
\hline Invites a prediction & Invites & $\begin{array}{l}\text { Invites child } \\
\text { to think } \\
\text { about what, } \\
\text { why, or how } \\
\text { things may } \\
\text { happen } \\
\text { based on } \\
\text { something } \\
\text { they } \\
\text { observed } \\
\text { or know } \\
\text { about the } \\
\text { content or } \\
\text { story line of } \\
\text { the show }\end{array}$ & $\begin{array}{l}\text { "What do } \\
\text { you think } \\
\text { this is } \\
\text { going to be } \\
\text { about?" }\end{array}$ & $\checkmark$ & & \\
\hline Extends idea & Extends & $\begin{array}{l}\text { Provides } \\
\text { context to } \\
\text { extend or } \\
\text { broaden } \\
\text { thinking } \\
\text { about an idea } \\
\text { or concept } \\
\text { presented in } \\
\text { the show }\end{array}$ & $\begin{array}{l}\text { "You know } \\
\text { there are } \\
\text { some other } \\
\text { things } \\
\text { besides fish } \\
\text { that light } \\
\text { up." }\end{array}$ & & $\checkmark$ & $\checkmark$ \\
\hline
\end{tabular}




\begin{tabular}{|c|c|c|c|c|c|c|}
\hline $\begin{array}{l}\text { Checks for } \\
\text { understanding }\end{array}$ & Checks & $\begin{array}{l}\text { Provide } \\
\text { scaffolding } \\
\text { or structure } \\
\text { to determine } \\
\text { that the child } \\
\text { has } \\
\text { understood } \\
\text { the story or } \\
\text { concept } \\
\text { presented in } \\
\text { the show }\end{array}$ & $\begin{array}{l}\text { "Can you } \\
\text { tell me } \\
\text { how } \\
\text { Bubbles } \\
\text { got her } \\
\text { moves } \\
\text { back? }\end{array}$ & & $\checkmark$ & $\sqrt{ }$ * \\
\hline $\begin{array}{l}\text { Connects to child } \\
\text { knowledge/experience }\end{array}$ & Connects & $\begin{array}{l}\text { Highlight the } \\
\text { child's } \\
\text { experiences } \\
\text { or everyday } \\
\text { life examples } \\
\text { that may } \\
\text { relate to the } \\
\text { story or } \\
\text { science } \\
\text { phenomena } \\
\text { in the show }\end{array}$ & $\begin{array}{l}\text { "If you } \\
\text { were in the } \\
\text { deep } \\
\text { ocean, why } \\
\text { would you } \\
\text { want a } \\
\text { flashlight?" }\end{array}$ & $\checkmark$ & $\checkmark$ & $\checkmark$ \\
\hline Other & Other & $\begin{array}{l}\text { Additional } \\
\text { move to } \\
\text { engage } \\
\text { child's } \\
\text { thinking that } \\
\text { is not } \\
\text { captured } \\
\text { otherwise }\end{array}$ & $\begin{array}{l}\text { "They're all } \\
\text { playing } \\
\text { hide and } \\
\text { seek." }\end{array}$ & $\checkmark$ & $\checkmark$ & $\checkmark$ \\
\hline
\end{tabular}

Findings from analyses of the talk moves indicate that intervention families tended to use two talk moves, asks a question and checks for understanding, more frequently than comparison families. While this difference is evident across before and after viewing episode prompts, the difference is more pronounced in the after viewing episode prompts. This finding suggests the app had a stronger effect promoting these specific types of conversation moves. See Figures 5 and 6. 
Figure 5

Frequency of "Asks a Question" and "Checks for Understanding" Talk Moves Before Episodes
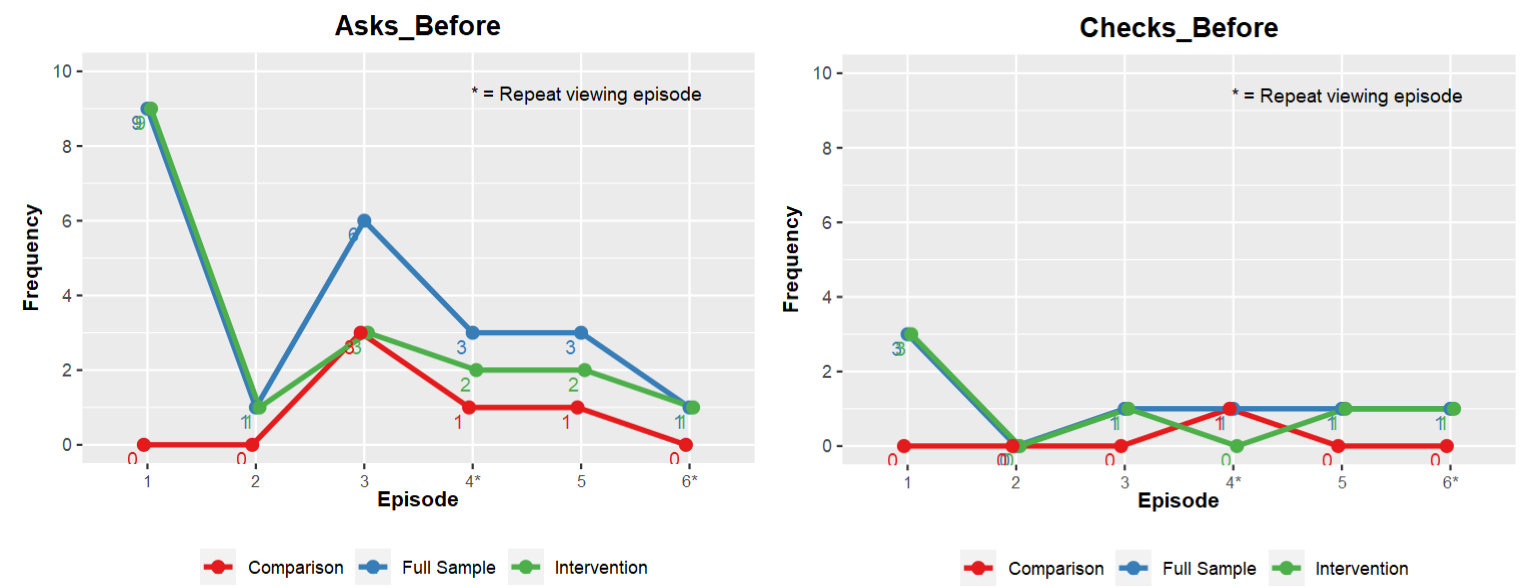

Figure 6

Frequency of "Asks a Question" and "Checks for Understanding" Talk Moves After Episodes
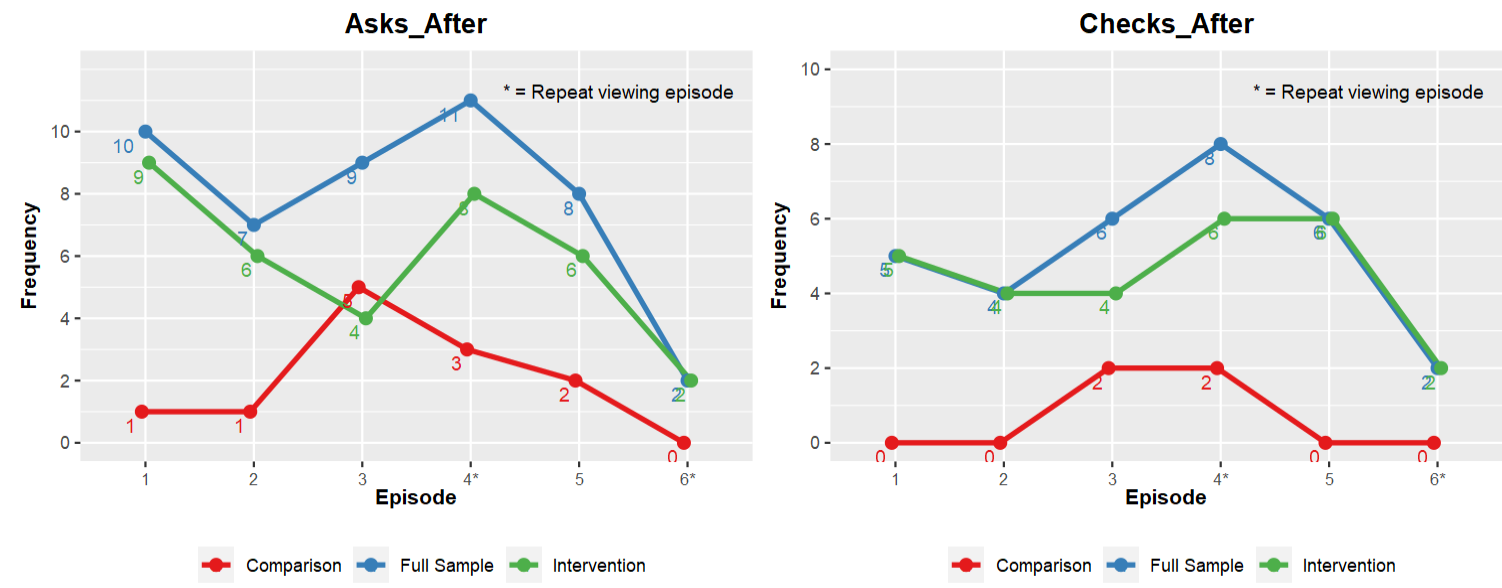


\section{Research Question 3: To what extent do joint engagements supported by the app support children's development of ocean science content knowledge and science practices?}

The team examined multiple data sources to measure child outcomes related to their ocean science content knowledge and science practices. More specifically, child assessment and text message data were used to measure children's science content knowledge, while childinitiated science conversations during the in-person sessions were used to measure their science talk.

A one-way ANCOVA was conducted to compare child post-assessment scores in the intervention and comparison groups while controlling for pre-assessment scores. Results indicated that there was not a statistically significant difference in post-test scores between groups, $F(1,13)=0.000264, p=0.987$. This finding is likely due to the fact that children learned the science core ideas from episode viewings rather than the app itself. The conversations prompted by the use of the app were more likely related to children's practices and discourse.

Child-initiated conversations were therefore analyzed to examine the potential impact of the app on children's science discourse. The findings were similar to those in the overall analyses of prompts that addressed science initiations of both adults and children (as a family unit). Although differences in the proportion of science-related conversation initiations by children were found in both before and after episode viewing, there were stronger differences in the after episode viewing. Of the child-initiated conversations, $25 \%$ of the intervention families' after episode viewing prompts were found to address science, while none of the prompts from comparison families were science related. For before episode viewing prompts, approximately $13 \%$ of the intervention families' prompts addressed science compared to approximately $8 \%$ of the comparison families' science-related prompts.

\section{Research Question 4: To what extent do parent/caregiver behaviors,} attitudes, and beliefs about educational media, ocean science, and family support for learning change as a result of engagement with the app?

Findings from self-reported surveys, interviews, and text message data indicate the promise of the Splash and Bubbles resources in helping parents/caregivers support their children's science learning.

At the end of Session 1, research assistants observing intervention families asked: "Did you find the app helpful or not? Why/ why not? What parts did you look at / use?" Three participants responded to this question. One found the app helpful and specifically pointed out the before questions and some of the introduction to characters. Another participant reported not finding it helpful due to a language barrier. The remaining participant was not able to elaborate on the helpfulness since they reported not knowing how to use the app. 
Between sessions, intervention parents/caregivers were asked via text message whether they had a chance to watch the assigned episodes with their child(ren). On one occasion between Session 2 and Session 3, six out of the seven intervention participants responded yes to the initial question and were asked a follow-up question: "This week, did you use the app when you were watching the episodes with your child?" Five out of the six intervention participants responded yes to the question and were asked another follow-up question: "Did you find the content in the app useful or interesting?" All five families that received the second follow up text message responded yes.

As mentioned previously, interview data suggest that families who internalized the intention of the app and explored its features thoroughly experienced the most significant changes in behaviors, attitudes, and beliefs. Families who expressed more confusion about the app (e.g., providing feedback that it would be better if it were designed to be a children's app) do not seem to have tried out the strategies or tools.

Two families, in particular, demonstrated strong evidence of changes in behavior as a result of interacting with the app. One family, a bilingual family living in San Francisco's Chinatown, demonstrated strong desire but low confidence in providing science-rich educational opportunities to their child, before participating in the study. When asked in the first interview about her survey response noting disagreement with the statement, I am a science person, the mother responded, "Sometimes the child is asking questions about the physical or nature, but I couldn't provide the right answer. It's hard to answer her the perfect answers. So I'm not [a science person]." The mother also described in her first interview a desire to support her child's learning by talking about shows and her interest in finding high-quality science shows. She understood the potential value for learning but, again, did not feel confident in her knowledge to find shows or apps that would be beneficial.

In the final interview, this parent described in detail the way that the app had supported her to engage more confidently with her child's science learning. The parent discussed the many questions her child asks and noted that the app gave her the information she needed to feel competent engaging with her child:

"She has lots of questions asked. And I had in app support to answer it. She was very interested in why shark didn't eat the little one. Something related to those questions. Before I used the app, I didn't know how to answer that. Sometimes we did discussion about that. I feel more confident to search the results. I know how to search for the areas like videos. To get more information and to talk to her."

The parent also specifically noted how the app gave her models of joint viewing strategies, sharing that, while she might have thought to talk with her child after viewing a show, she hadn't considered engaging in dialogue before the show until she used the app. The parent shared in her final interview that because of the show's app, "I feel more confident engaging in science talk with my child."

A second family, also a bilingual family living in a low-income urban community, demonstrated a similar pattern of high interest yet low confidence related to science 
engagement, prior to participation in the study, and impressive self-reported behavior/ attitudinal change. This family reported going on annual family camping trips, seeking out television shows with science content, and engaging in simple experiments. Yet the parent was also clear in the preliminary interview that she does not feel confident answering her children's science queries, referring them to their father.

Use of the app strengthened this mother's interest and confidence related to science engagement with her children, "[I] became more interested in science, know more things to talk with son, especially with the app.... It's a good app, having conversations with my son and he can also ask me questions. Having a reference is very helpful."

This mother specifically noted the value of educational technology, like the app, that encourages her child to learn through conversation with her. She compared this to other media that may engage her child but do not lead to learning-rich dialogue: "Even though it's technology, it's educational. A lot of the games they play aren't and they don't talk to me about it. But this is good because I can talk to my son and ask him questions and learn too. It's a great privilege for us and hope other parents can have it too. Very thankful for all of it."

\section{Reference}

Clement, J. (2019, January 29). Second screen usage - statistics \& facts. Statista. Retrieved October 10, 2015, from http://www.statista.com/topics/2531/second-screen-usage/

\section{Appendix A. Episode Curation and Schedule}

This outlines the curated content and schedule for participating intervention and comparison families, which included Splash and Bubbles episodes, interstitials, and activities from the app.

\begin{tabular}{|l|l|l|l|l|l|}
\hline Week & Title & $\begin{array}{l}\text { Content } \\
\text { Type } \\
\text { (Episode, } \\
\text { Interstitial, } \\
\text { Activity) }\end{array}$ & $\begin{array}{l}\text { Science Core } \\
\text { Idea }\end{array}$ & $\begin{array}{l}\text { Intervention } \\
\text { Group }\end{array}$ & $\begin{array}{l}\text { Comparison } \\
\text { Group }\end{array}$ \\
\hline $\begin{array}{l}\text { Week 1: } \\
\text { Session 1 }\end{array}$ & $\begin{array}{l}\text { Here Comes the } \\
\text { Hammerhead }\end{array}$ & Episode & $\begin{array}{l}\text { Structure and } \\
\text { Function }\end{array}$ & $\checkmark$ & $\checkmark$ \\
\cline { 2 - 6 } & $\begin{array}{l}\text { Lu, Bob and } \\
\text { Mayor Sting }\end{array}$ & Interstitial & & $\checkmark$ & $\checkmark$ \\
\cline { 2 - 6 } & Lu the Explorer & Episode & Adaptations & $\checkmark$ & $\checkmark$ \\
\hline
\end{tabular}




\begin{tabular}{|c|c|c|c|c|c|}
\hline \multirow[t]{3}{*}{$\begin{array}{l}\text { Week 2: } \\
\text { At home }\end{array}$} & $\begin{array}{l}\text { I Only Have } \\
\text { Eyespots for } \\
\text { You }\end{array}$ & Episode & $\begin{array}{l}\text { Structure and } \\
\text { Function }\end{array}$ & $\checkmark$ & $\checkmark$ \\
\hline & $\begin{array}{l}\text { Ultimate Hide } \\
\text { and Seek }\end{array}$ & Episode & Adaptations & $\checkmark$ & $\checkmark$ \\
\hline & $\begin{array}{l}\text { Hiding in Plain } \\
\text { Sight }\end{array}$ & Activity & & $\checkmark$ & \\
\hline \multirow[t]{5}{*}{$\begin{array}{l}\text { Week 3: } \\
\text { At home }\end{array}$} & $\begin{array}{l}\text { Here Comes the } \\
\text { Hammerhead* }\end{array}$ & Episode & $\begin{array}{l}\text { Structure and } \\
\text { Function }\end{array}$ & $\checkmark$ & $\checkmark$ \\
\hline & $\begin{array}{l}\text { The House } \\
\text { Hunt }\end{array}$ & Episode & $\begin{array}{l}\text { Interdependent } \\
\text { relationships }\end{array}$ & $\checkmark$ & $\checkmark$ \\
\hline & Dunk's Cleaning & Episode & $\begin{array}{l}\text { Interdependent } \\
\text { relationships }\end{array}$ & $\checkmark$ & $\checkmark$ \\
\hline & $\begin{array}{l}\text { The Cleaning } \\
\text { Station }\end{array}$ & Interstitial & & $\checkmark$ & $\checkmark$ \\
\hline & Extreme Clean & Episode & $\begin{array}{l}\text { Interdependent } \\
\text { relationships }\end{array}$ & $\checkmark$ & $\checkmark$ \\
\hline \multirow[t]{3}{*}{$\begin{array}{l}\text { Week 4: } \\
\text { Session } 2\end{array}$} & From Ray to Zee & Episode & $\begin{array}{l}\text { Structure and } \\
\text { Function }\end{array}$ & $\checkmark$ & $\checkmark$ \\
\hline & Stingrays & Interstitial & & $\checkmark$ & $\checkmark$ \\
\hline & $\begin{array}{l}\text { Dunk's } \\
\text { Cleaning* }\end{array}$ & Episode & $\begin{array}{l}\text { Interdependent } \\
\text { relationships }\end{array}$ & $\checkmark$ & $\checkmark$ \\
\hline \multirow[t]{4}{*}{$\begin{array}{l}\text { Week 5: } \\
\text { At home }\end{array}$} & $\begin{array}{l}\text { Chompy's New } \\
\text { Food }\end{array}$ & Episode & $\begin{array}{l}\text { Interdependent } \\
\text { relationships }\end{array}$ & $\checkmark$ & $\checkmark$ \\
\hline & Parrotfish Song & Interstitial & & $\checkmark$ & $\checkmark$ \\
\hline & Sand is Grand & Episode & $\begin{array}{l}\text { Interdependent } \\
\text { relationships }\end{array}$ & $\checkmark$ & $\checkmark$ \\
\hline & Happy Habitats & Activity & & $\checkmark$ & \\
\hline
\end{tabular}




\begin{tabular}{|l|l|l|l|l|l|}
\hline \multirow{4}{*}{$\begin{array}{l}\text { Week 6: } \\
\text { At home }\end{array}$} & $\begin{array}{l}\text { Golden Legs } \\
\text { Gush }\end{array}$ & Episode & $\begin{array}{l}\text { Structure and } \\
\text { Function }\end{array}$ & $\checkmark$ & $\checkmark$ \\
\hline & $\begin{array}{l}\text { Gush's White } \\
\text { Whale }\end{array}$ & Episode & Adaptations & $\checkmark$ & $\checkmark$ \\
\hline & $\begin{array}{l}\text { Oblo from } \\
\text { Down Below }\end{array}$ & Episode & Adaptations & $\checkmark$ & $\checkmark$ \\
\hline & \begin{tabular}{l} 
Mo's Sunburn \\
\cline { 2 - 6 }
\end{tabular} & Episode & Adaptations & $\checkmark$ & $\checkmark$ \\
\hline & $\begin{array}{l}\text { The Deep } \\
\text { Ocean }\end{array}$ & Interstitial & & $\checkmark$ & $\checkmark$ \\
\hline Week 7: & $\begin{array}{l}\text { How Bubbles } \\
\text { Got Her Moves } \\
\text { Back }\end{array}$ & Episode & $\begin{array}{l}\text { Structure and } \\
\text { Function }\end{array}$ & $\checkmark$ & $\checkmark$ \\
\hline & $\begin{array}{l}\text { Oblo from } \\
\text { Down Below* }\end{array}$ & Episode & Adaptations & $\checkmark$ & $\checkmark$ \\
\hline & $\begin{array}{l}\text { Exploring } \\
\text { Adaptations }\end{array}$ & Activity & & $\checkmark$ & \\
\hline
\end{tabular}

